\title{
Effect of retreating sea ice on Arctic cloud cover in simulated recent global warming
}

\author{
Manabu Abe ${ }^{1}$, Toru Nozawa ${ }^{2}$, Tomoo Ogura $^{3}$, and Kumiko Takata ${ }^{3,4}$ \\ ${ }^{1}$ Department of Integrated Climate Change Projection Research, Project Team for Risk Information on Climate Change, \\ Institute of Arctic Climate and Environment Research, Japan Agency for Marine-Earth Science and Technology, \\ 3173-25 Showa-machi, Kanazawa-ku, Yokohama 236-0001, Japan \\ ${ }^{2}$ Graduate school of Nature Science and Technology, Okayama University, 3-1-1 Tsushima-naka, Kita-ku, \\ Okayama 700-8530, Japan \\ ${ }^{3}$ Center for Global Environmental Research, National Institute for Environmental Studies, 16-2 Onogawa, \\ Tsukuba 305-8506, Japan \\ ${ }^{4}$ Arctic Environment Research Center, National Institute of Polar Research, 10-3 Midori-cho, Tachikawa 190-8518, Japan \\ Correspondence to: Manabu Abe (abe.mnb@gmail.com)
}

Received: 31 May 2016 - Published in Atmos. Chem. Phys. Discuss.: 24 June 2016

Revised: 13 October 2016 - Accepted: 28 October 2016 - Published: 18 November 2016

\begin{abstract}
This study investigates the effect of sea ice reduction on Arctic cloud cover in historical simulations with the coupled atmosphere-ocean general circulation model MIROC5. Arctic sea ice has been substantially retreating since the 1980s, particularly in September, under simulated global warming conditions. The simulated sea ice reduction is consistent with satellite observations. On the other hand, Arctic cloud cover has been increasing in October, with about a 1-month lag behind the sea ice reduction. The delayed response leads to extensive sea ice reductions because the heat and moisture fluxes from the underlying open ocean into the atmosphere are enhanced. Sensitivity experiments with the atmospheric part of MIROC5 clearly show that sea ice reduction causes increases in cloud cover. Arctic cloud cover increases primarily in the lower troposphere, but it decreases in the near-surface layers just above the ocean; predominant temperature rises in these near-surface layers cause drying (i.e., decreases in relative humidity), despite increasing moisture flux. Cloud radiative forcing due to increases in cloud cover in autumn brings an increase in the surface downward longwave radiation (DLR) by approximately $40-60 \%$ compared to changes in clear-sky surface DLR in fall. These results suggest that an increase in Arctic cloud cover as a result of reduced sea ice coverage may bring further sea ice retreat and enhance the feedback processes of Arctic warming.
\end{abstract}

\section{Introduction}

Satellite observations have shown that Arctic sea ice has decreased gradually since the 1980s (Comiso et al., 2008). Recent significant reductions in Arctic sea ice occurred in 2007 and 2012. A further reduction in Arctic sea ice is likely to result from future global warming. In turn, the reduction in sea ice can accelerate surface warming in the Arctic region through various feedback processes. A major feedback process in climate change is the ice-albedo feedback, in which reduced sea ice decreases the global albedo and increases shortwave radiation entering the climate system (e.g.,Curry et al., 1995; Dickinson et al., 1987; Manabe and Stouffer, 1980; Perovich et al., 2007). This feedback is likely to occur in high-latitude regions, where snow cover and sea ice are seasonally extended. However, as Yoshimori et al. (2014) mentioned with regard to the climate model results that Arctic surface warming in autumn-winter is attributed to a seasonal reduction in ocean heat storage and an increased cloud greenhouse effect, other processes such as ocean heat uptake, atmospheric stability, and low-level cloud response may require further attention to better understand the Arctic warming mechanism.

The reduction in sea ice also involves other feedback processes in the Arctic region (Serreze and Barry, 2011). Previous studies have suggested that extended periods of open 
ocean resulting from reductions in sea ice increase Arctic cloud cover and enhance Arctic amplification (e.g., Holland and Bitz, 2003; Screen and Simmonds, 2010; Serreze and Barry, 2011; Vavrus et al., 2009; Yoshimori et al., 2014). Liu et al. (2012) used satellite data to show that a $1 \%$ decrease in sea ice concentration leads to a $0.36-0.47 \%$ increase in cloud cover. These authors also suggested that the total variance in cloud cover from July to November can be explained by the sea-ice-cloud feedback. Recent ship observations have found that cloud base heights tend to increase in September over the Arctic Ocean without sea ice cover due to heating from the ocean (Sato et al., 2012). This heating is enhanced because of the increased temperature gradient between the atmosphere and the ocean, weakening the stable conditions in the atmospheric boundary layer. This previous study indicated that convective clouds become more numerous over the Arctic Ocean. However, whereas Kay and Gettelman (2009) showed that increased turbulent transport of heat and moisture promotes low-cloud formation, Schweiger et al. (2008) showed that low-level clouds may decrease and middle-level clouds simultaneously increase in coverage because the decreased static stability and a deepening atmospheric boundary layer contribute to a rise in the cloud level. Simulations run by Porter et al. (2012) with the Weather Research Forecasting (WRF) model support an increase in middle-level clouds in September and increases in low-level cloud cover from October to November. The cloud cover change resulting from sea ice loss and its vertical profile are under debate.

Wu and Lee (2012) suggested that the enhanced downward longwave radiation (DLR) resulting from increased cloud cover may have been responsible for the enhanced autumnal increase in the surface air temperature (SAT). In addition, the enhanced DLR can prolong the sea ice melt seasons and lead to a positive feedback involving Arctic sea ice loss (Serreze and Barry, 2011). However, Schweiger et al. (2008) concluded that the radiative effect of this change is relatively small because the direct radiative effects of cloud cover changes are compensated for by changes in the temperature and humidity profiles associated with varying ice conditions. A regional climate model simulation has also shown that the radiative effect of cloud cover changes is likely to be smaller than that of changes in air temperature and humidity (Rinke et al., 2013). Because of the deficiency in observed radiation data at the surface, the radiative effect of cloud clover changes in the Arctic warming remains controversial.

In addition to the analysis of observations, several studies have employed climate model simulations. Climate models that have simulated sea ice reduction show that Arctic cloud cover increases in fall (Vavrus et al., 2009, 2011). An increased area of open ocean enhances the heat and moisture transport from the ocean to the atmosphere, resulting in increased cloudiness. These studies have analyzed the change in cloudiness resulting from sea ice losses in simulations with increased greenhouse gas concentrations. The effects of reduced sea ice in these analyses are stronger than those oc- curring in the late 20th century. Therefore, these results are not always appropriate for the change in Arctic cloudiness that has occurred since the late 20th century, in which sea ice has only decreased in limited regions. These investigations may be insufficient to understand recently observed events and may not effectively explain recent processes in simulated climate models.

As noted above, several studies have investigated Arctic cloud cover changes during recent global warming. However, debate surrounds the change in Arctic cloudiness and the lack of an understanding of the effect of reduced sea ice on Arctic cloud cover because of insufficient observational data and long-standing difficulties in representing realistic polar clouds in climate models. In addition, the radiative effect of cloud cover changes at the surface is difficult to accurately measure because of the dark seasons and sea ice cover. In this study, we investigate the temporal trends of Arctic cloud cover changes during recent global warming simulated by a state-of-the-art climate model (i.e., MIROC5) and focus on the effects of reduced sea ice. The simulated vertical structure of cloud cover change is analyzed using a composite analysis technique because of continued controversy regarding the vertical profile of cloud changes. Furthermore, to provide information on the role of Arctic clouds in the mechanism of Arctic warming, this study evaluates the relative importance of changes in cloud radiative forcing on the surface DLR versus those due to increased air temperature and water vapor. The Arctic cloud cover changes resulting from reduced sea ice in climate model simulations should be informative for understanding the mechanism underlying future changes in Arctic clouds and Arctic warming.

The next section explains the coupled atmosphere-ocean general circulation model, MIROC5, used in this study and its 20th century simulation. The third section reports the results for the Arctic cloud cover changes resulting from retreating sea ice and for causality between changes in Arctic cloud cover and sea ice by the lead-lag correlation analysis of the historical simulations and the sensitivity experiments with the atmospheric general circulation model (GCM). We then discuss the relationship between changes in Arctic cloud cover and sea ice changes, and the paper concludes with a summary.

\section{Model and Experiments}

We analyze historical simulations using a coupled atmosphere-ocean general circulation model, i.e., MIROC5 (Watanabe et al., 2010), which was used in the Coupled Model Intercomparison Project Phase 5 (CMIP5). The atmospheric portion of MIROC5 is based on the global spectral dynamical core and includes a standard physical package. The atmospheric resolution is T85L40, with a top at $3 \mathrm{hPa}$. The ocean general circulation model in MIROC5 is the CCSR (Center for Climate System Research, University 
of Tokyo) Ocean Component Model (COCO) version 4.5 (Hasumi, 2007). The zonal resolution of the ocean is fixed at $1.4^{\circ}$, whereas the meridional resolution is $0.5^{\circ}$ at latitudes equatorward of 8 and $1.4^{\circ}$ at higher latitudes (poleward of $\left.65^{\circ}\right)$, with a smooth transition in between $(256 \times 224$ grid points for the zonal and meridional directions, respectively). The model has 49 vertical levels, and the spacing varies with a depth of $2.5 \mathrm{~m}$ at the surface, $20 \mathrm{~m}$ at a depth of $100 \mathrm{~m}, 100 \mathrm{~m}$ at a depth of $1000 \mathrm{~m}$, and $250 \mathrm{~m}$ below a depth of $2000 \mathrm{~m}$. The sea ice in each horizontal grid is divided into five ice thickness categories in addition to open water. The lower bounds of ice thickness for these categories are $0.3,0.6,1.0,2.5$, and $5.0 \mathrm{~m}$. The sea ice concentration, ice thickness, and energy of ice melting are predicted for the five categories in a grid cell (Komuro et al., 2012). In the sea ice model, thermodynamic variables for each category, such as sea ice concentration and thickness, are advected by the sea ice horizontal velocity, which conserves ice volume and is common for all categories in a grid.

Historical simulations are performed from 1850 to 2005 using anthropogenic forcings recommended by the CMIP5 project. In the simulation, changes in the solar constant are applied according to Lean et al. (2005). Also, the optical thickness of volcanic stratospheric aerosols is given by Sato et al. (1993), and subsequent updates are available (http:// data.giss.nasa.gov/modelforce/strataer/). Beginning in 1998, the optical thickness of the volcanic stratospheric aerosols is assumed to exponentially decrease with a 1-year relaxation time.

The historical simulation using MIROC5 has five ensemble members with different initial conditions. In this study, monthly mean data are used, and sea ice concentration data are interpolated to correspond with the atmospheric horizontal grids.

To further examine the effect of reduced sea ice on Arctic cloud cover, we conducted systematic sensitivity experiments with MIROC5 atmospheric GCM (AGCM). In the sensitivity experiments, the Arctic cloud cover under different combinations of sea surface temperature (SST) and sea ice conditions in the 1980 s and 2000s was compared. Additionally, the impact of changes in other forcings, such as greenhouse gases, aerosols, and land use, from the 1980s to 2000 s on the Arctic cloud cover were examined. Table 1 shows the SST, sea ice, and other forcing conditions. These experiments used climatological monthly mean SST and sea ice data, which were obtained from historical MIROC5 simulations. The SST and SIC in the 1980s were averaged over the period 1976-1985 in the historical simulations. Both the SST and SIC in the 2000s comprised additive data from the 1980s and changes for the following 20 years, which were estimated using the linear trend from 1976 to 2005 in the historical simulations. Because we had five ensemble members in the historical simulations, each of the sensitivity experiments consisted of five ensemble members, in which combinations of the SST and sea ice based on each member of the histor-
Table 1. Sea surface temperature (SST), sea ice, and other forcing conditions in the sensitivity experiments with MIROC5-AGCM. Other forcings include land use, greenhouse gas concentrations, aerosol emissions, and total solar irradiance. Data in the 1980s indicate an average over the period 1976-1985, and the data in the 2000s combine data for the 1980s and changes for the following 20 years, which were estimated using the linear trend from 1976 to 2005 in the historical simulations. Each experiment name except CTL indicates changes of the condition from CTL. The letters SI, SST, OF, and ALL before 2000 in the name indicate that, respectively, sea ice, SST, other (atmospheric) forcings and all the three conditions for 2000 or the 2000s were used in the experiment rather than using those for 1980 or the 1980s, as indicated by 2000 or 2000s (bold) in the table.

\begin{tabular}{lccc}
\hline Exp. name & Sea ice (SI) & SST & Other forcing (OF) \\
\hline CTL & $1980 s$ & $1980 s$ & 1980 \\
OF2000 & $1980 s$ & $1980 s$ & $\mathbf{2 0 0 0}$ \\
SSTOF2000 & $1980 s$ & $\mathbf{2 0 0 0 s}$ & $\mathbf{2 0 0 0}$ \\
SIOF2000 & $\mathbf{2 0 0 0 s}$ & $1980 \mathrm{~s}$ & $\mathbf{2 0 0 0}$ \\
ALL2000 & $\mathbf{2 0 0 0 s}$ & $\mathbf{2 0 0 0 s}$ & $\mathbf{2 0 0 0}$ \\
\hline
\end{tabular}

ical simulations were prescribed. Other forcing conditions, such as greenhouse gases, aerosols, and total solar irradiance, in the control (CTL) and other simulations corresponded to those in 1980 and 2000. The sensitivity experiments were integrated for 30 years, and the last 20 years were used in this analysis. Results of the sensitivity experiments are described in Sect. 3.2.2.

The time series of SAT anomalies ( $\triangle \mathrm{SAT}$ ) from the $1951-$ 1980 average, which were averaged both globally and for the high-latitude regions $\left(60-90^{\circ} \mathrm{N}\right)$ during the period 1900 2005, are shown in Fig. 1a. A small increasing trend in the global mean $\triangle$ SAT occurred during the period 1900-1960, although the interannual variations of the global mean $\triangle$ SAT were dominant. Since the 1970 s, the global mean $\Delta$ SAT has increased. The increasing trend in the global mean $\triangle \mathrm{SAT}$ was approximately $0.2 \mathrm{Kdecade}^{-1}$. Conversely, the $\triangle \mathrm{SAT}$ $\left(60-90^{\circ} \mathrm{N}\right)$ varied between -1.0 and $+1.0^{\circ} \mathrm{C}$ until 1970 . The $\triangle \mathrm{SAT}\left(60-90^{\circ} \mathrm{N}\right)$ began to increase in the $1970 \mathrm{~s}$, reaching $1{ }^{\circ} \mathrm{C}$ in the 2000s. The warming rate from 1976 to 2005 was approximately $0.6 \mathrm{~K} \mathrm{decade}^{-1}$, which is at least twice as high as the warming rate for the global mean $\triangle$ SAT. This result clearly reveals the Arctic amplification (AA), indicating that MIROC5 is able to simulate the AA in historical simulations. The positive trend for $\triangle \mathrm{SAT}\left(60-90^{\circ} \mathrm{N}\right)$ for the period 1970-2005 in MIROC5 agrees with the observationally based $\triangle \mathrm{SAT}\left(60-90^{\circ} \mathrm{N}\right)$ data from the Merged Land and Ocean Temperature Analysis (MLOST) (Smith et al., 2008), HadCRUT4 (Morice et al., 2012), and GISS Surface Temperature Analysis (GISTEMP) (Hansen et al., 2010).

The time series of the September Arctic sea ice area (SIA) is shown in Fig. 1b. As the SAT in the northern high latitude increased, the Arctic SIA significantly decreased. This 


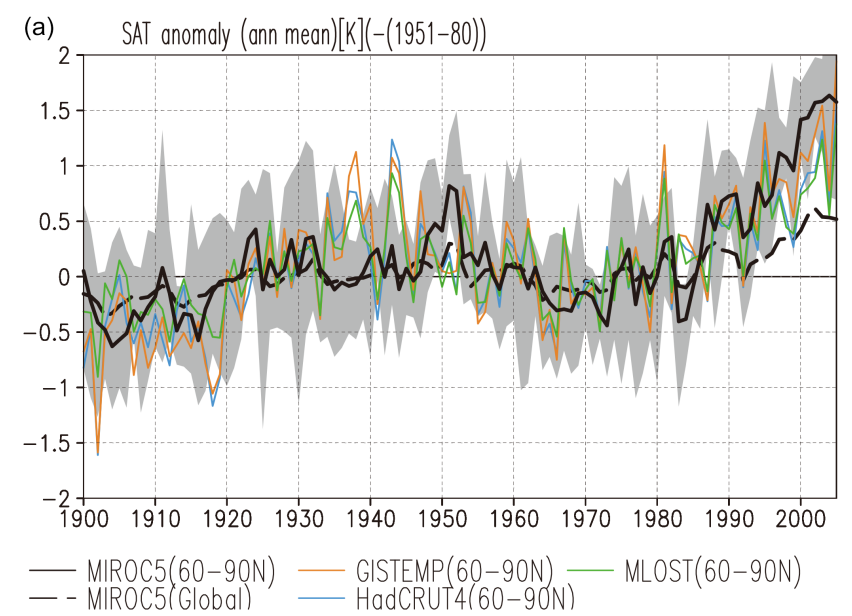

(b) Sep. arctic sea ice area $\left[* 10^{6} \mathrm{~km}^{2}\right]$

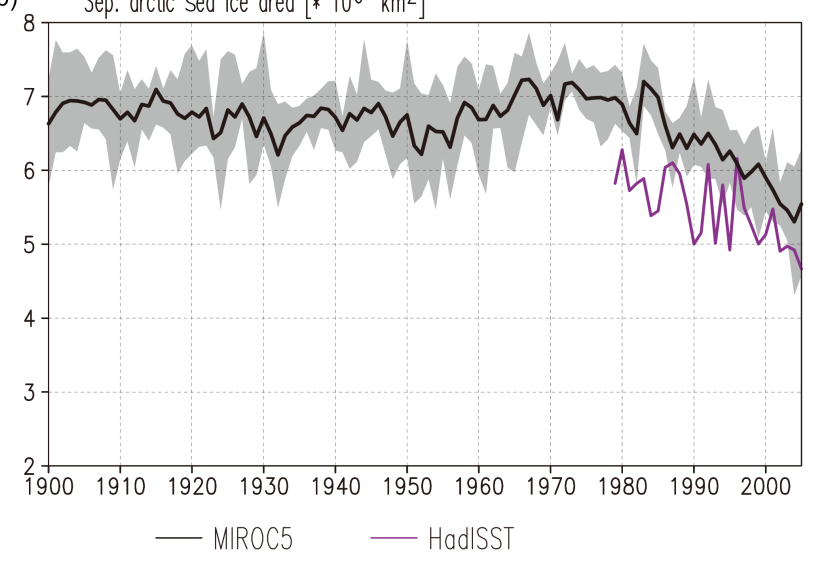

Figure 1. (a) Time series of the surface air temperature (SAT) anomaly from the 1951-1980 mean. Solid black, green, orange, and blue lines are the SAT anomalies averaged over $60-90^{\circ} \mathrm{N}$ in MIROC5's ensemble mean, MLOST, GISTEMP, and HadCRUT4, respectively. The broken black line is the global and ensemble mean SAT anomaly in MIROC5. The gray shaded area indicates the maximum and minimum SAT anomalies between the ensemble members of MIROC5. (b) Time series of the September sea ice extent. The black lines represent the ensemble mean. The gray shaded area indicates the maximum and minimum ensemble members. The purple line is the September sea ice extent calculated from HadISST. The units of the SAT anomaly and sea ice extent anomaly are $\mathrm{K}$ and $10^{6} \mathrm{~km}^{2}$, respectively.

decrease from the 1970s was common in all ensemble members. This simulated negative trend in the Arctic SIA averaged for ensemble members agrees with that from the Hadley Center Sea Ice and Sea Surface Temperature data set (HadISST) (Rayner et al., 2003), although the simulated SIA is slightly larger than that from the HadISST.

\section{Results}

\subsection{Simulated change of Arctic sea ice and clouds}

According to observations, the seasonal minimum SIA occurs in September, and Arctic sea ice cover generally begins to recover in October. The overall feature of the Arctic SIA seasonal cycle (e.g., summer reduction and fall recover) were reproduced by MIROC5, though there are small differences between the observations and simulations (Komuro et al., 2012). Figure 2 a shows the simulated seasonal SIA cycle in MIROC5, averaged for the periods 1976-1985 (blue line) and 1991-2005 (red line), has a maximum in March and a minimum in August. Figure $2 \mathrm{~b}$ displays the changes in the simulated seasonal cycle between the two periods, 1976 1985 and 1991-2005. The decreases in the simulated Arctic SIA in all months and the maximum reduction in September, consistent with observations of the Arctic SIA (Comiso et al., 2008) and probably due to recent global warming, are found.

As for the simulated cloud cover averaged over the Arctic Ocean (Fig. 2c and d), low-level cloud cover is at maximum of $50 \%$ in summer and continuously decreases during fall and winter, reaching a minimum in April. The simulated seasonal amplitude of the total cloud cover was similar to that of the low-level clouds; the seasonal cycle of the total cloud cover can be explained by the low-level clouds in MIROC5. The seasonal cycle of the total cloud cover averaged over the Arctic Ocean by MIROC 5 was similar to the observed climatological ones by the TIROS Operational Vertical Sounder (TOVS) satellite (Schweiger et al., 1999) and surface observations (Hahn et al., 1995). The simulated Arctic cloud cover for fall, winter, and spring increased between two periods (1976-1985 and 1996-2005; Fig. 2d), although the change was not substantial. The largest increase in simulated cloud cover in October agrees with previous studies using satellite data and climate model simulations (Liu et al., 2012; Vavrus et al., 2011; Wu and Lee, 2012).

The geographical match of the reduction in sea ice and the increase in cloud cover in the Arctic Ocean is crucial to discuss the interaction between changes in sea ice and cloud cover in the Arctic Ocean. The geographical distributions of the simulated linear trends in total cloud cover and sea ice concentrations (SICs) from 1976 to 2005 in September, October, and November are shown in Fig. 3. The linear trends were calculated using the least squares method in each grid and tested for statistical significance to determine whether the trend was zero using a $t$ test. In September (Fig. 3a), negative trends in SIC were found over the Laptev Sea, the East Siberian Sea, and the Beaufort Sea, in addition to those in the Atlantic sector, the Kara Sea, and the Barents Sea. As for cloud cover, only a small increasing trend appeared on the coast of the East Siberian Sea and the northern Bering Strait.

Negative trends in SICs remained in October (Fig. 3b), although the area with substantial negative trends became smaller than that in September. However, the positive trends 
(a) Arctic sea ice area $\left[* 10^{6} \mathrm{~km}^{2}\right]$ MIROC5

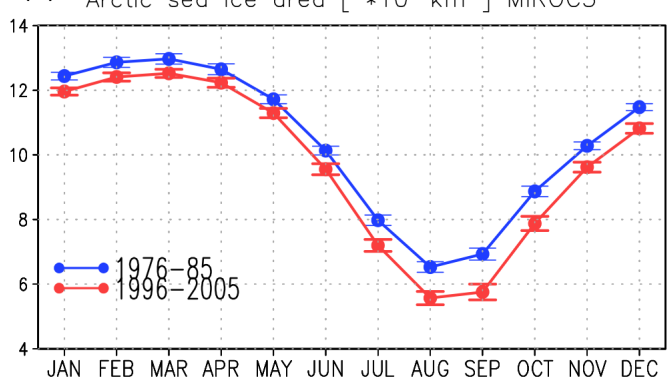

(b) Diff. sea ice area $(1996-2005)-(1976-85)\left[* 10^{6} \mathrm{~km}^{2}\right]$ MIROC5

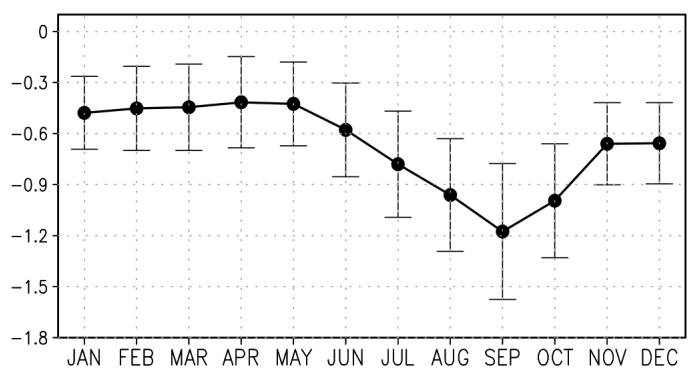

(c)

Arctic mean cloud cover (MIROC5)

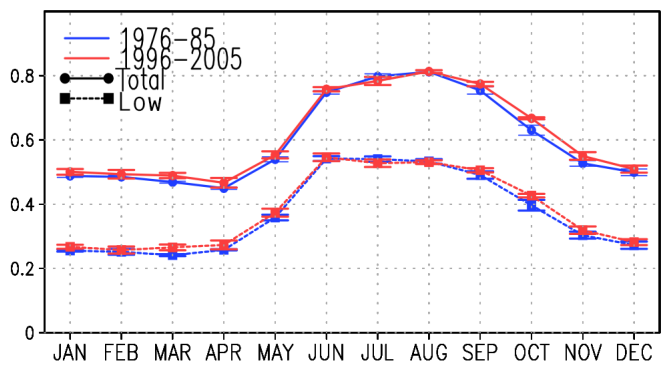

(d) Diff. cloud cover (1996-2005)-(1976-85) MIROC5

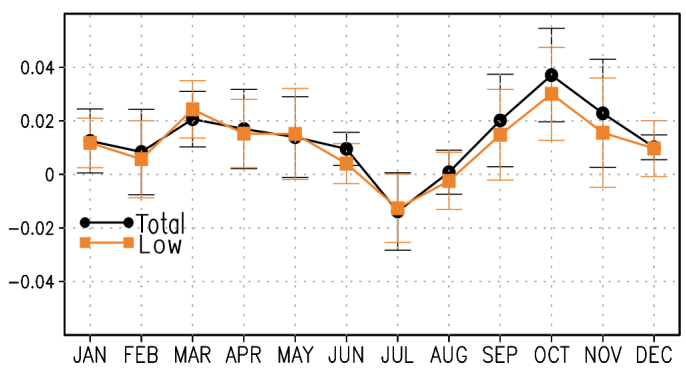

Figure 2. Seasonal cycle of (a) Arctic mean sea ice area averaged over the periods 1976-1985 and 1996-2005 in MIROC5 and (b) the difference between the means; (c) and (d) are identical to (a) and (b) except for the total and low cloud covers. The unit of sea ice area is $10^{6} \mathrm{~km}^{2}$.

in cloud cover expanded broadly over the Arctic Ocean. In the region of the East Siberian, Chukchi, and Beaufort seas, where SICs showed markedly decreasing trend, the larger positive trends in cloud cover were found. At the same time, the heights of the simulated cloud tops and bases increased predominantly in regions with the large reductions in SIC during October, which was also common in September. These results imply that increased cloud cover was caused by the reduction in SICs. It is noteworthy that the simulated cloud cover increased substantially over the Arctic Ocean north of the Beaufort Sea without large negative trends in the simulated SIC. On the other hand, there is no significant positive trend in cloud cover with the substantial SIC reduction in the Barents Sea and near Greenland. It is possible that in the Barents Sea and near Greenland, the dynamic impact in the atmosphere from the lower latitudes may weaken the thermodynamic effect resulting from the increased open ocean in some ensemble members in MIROC5 simulations, since there were major atmospheric flows from the lower latitude during fall in these regions.

In November (Fig. 3c), the large negative trends in SIC were limited to the Barents Sea, the Bering Strait, and the coasts of Greenland with a significant increase in cloud cover. This result also supports the idea that cloud cover increases because of reduced sea ice. In winter, cloud cover increased over grids with reduced sea ice, similar to that in November. However, the change in the simulated Arctic cloud cover in November and winter was less dominant than that in October because the sea ice reductions were smaller.
In the following sections, the increased cloud cover in October is examined.

\subsection{Causality between changes in Arctic sea ice and cloud}

\subsubsection{Autocorrelation and lead-lag correlation analysis}

We have analyzed causality between reductions in SIC and increasing cloud cover with the autocorrelation and lead-lag correlation analysis during 1976-2005. In addition to negative correlation between cloud cover and SIC in October, negative correlation between cloud cover in October and sea ice in September would mean that a reduction in sea ice causes an increase in cloud cover. Figures $4 a$ shows the geographical distribution of 1-month-lagged autocorrelations of sea ice concentrations between September and October, and Fig. 4b shows instantaneous correlations of cloud cover and sea ice concentrations in October. For the autocorrelation in sea ice concentration between September and October, large positive correlation coefficients were found over most of the Arctic Ocean; the correlation coefficient exceeded 0.6 from the Beaufort Sea to the Barents Sea (Fig. 4a). As for the temporal changes of the autocorrelation in the representative subregion of the Arctic Ocean $\left(109-221^{\circ} \mathrm{E}, 69-78^{\circ} \mathrm{N}\right)$, shown with the broken line in Fig. 4a, they were high for SIC (blue circle in Fig. 4c) and become low in early and late months more slowly than cloud cover (black circle in Fig. 4c). This is because SIC has a substantially longer mem- 
Trend (1976-2005) [decade ${ }^{-1}$ ]

Sea ice concentration \& total cloud cover
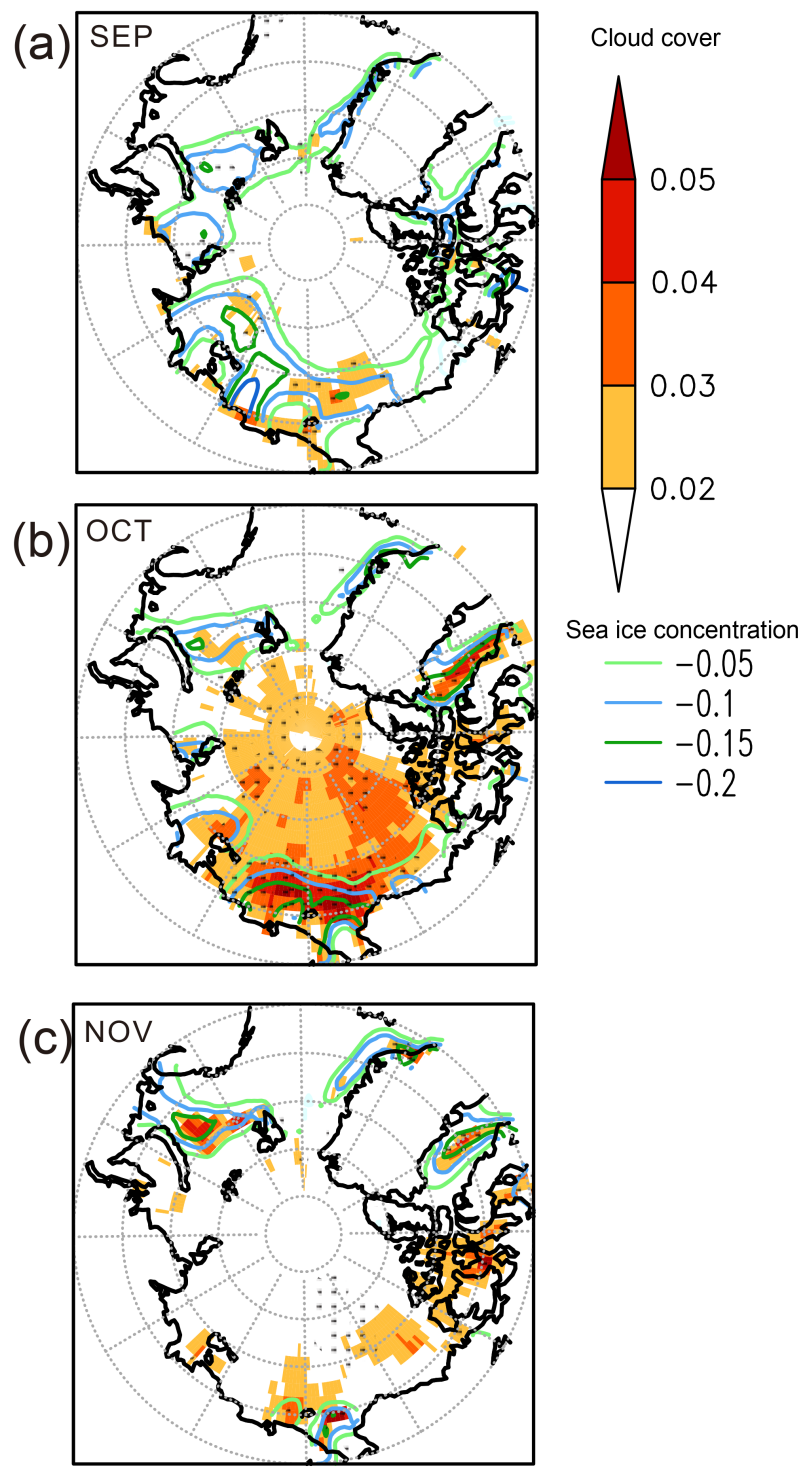

Figure 3. Geographical map of the simulated linear trend in the total cloud cover (shaded) and sea ice concentration (contours) in (a) September, (b) October, and (c) November during the period 1976-2005. The units are decade ${ }^{-1}$. Dots indicate that the linear trend is not zero at the $95 \%$ significance level.

ory than cloud cover. These results imply that sea ice changes in October tend to depend on sea ice changes in September in MIROC5; i.e., small SIC in September is likely to results in small SIC in October.

Stronger negative correlations between SIC and cloud cover in October were found in the grids with large negative trends in SIC during 1976-2005 (Fig. 4b). This means that the increased cloud cover was associated with a smaller
SIC. The negative relationship between SIC and cloud cover in MIROC5 agrees with the observed results in Palm et al. (2010) and Liu et al. (2012). Lead-lag correlations in the Arctic subregion demonstrated that cloud cover in October was negatively correlated with the lead/lagged SIC (red diamond in Fig. 4c). For instance, the red diamond for a lead/lag of $-1(+1)$ represents where SIC in September (November) leads (lags) cloud cover in October. This negative correlation of cloud cover in October with SIC in September suggested that small SIC continuing from September led to increased cloud cover in October. In addition, the autocorrelation of the cloud cover between September and October (approximately 0.42 ) was weaker than the negative correlation between the cloud cover in October and SIC in September (approximately -0.6 ), hence the increased cloud cover in October is unlikely to represent a continuing increase in cloud cover from September in MIROC5. However, SIC in October was also negatively correlated with lead/lagged cloud cover (green diamond in Fig. 4c). The green diamond for a lead/lag of $-1(+1)$ represents where cloud cover in September (November) leads (lags) SIC in October. The correlation of SIC in October and cloud cover in September (green diamond) was weaker than that of cloud cover in October and SIC in September (red diamond), as shown at an abscissa -1 of the lead/lag month in Fig. 4c. Therefore, we concluded that cloud cover is likely to increase due to a decrease in SIC during October in MIROC5. This result agrees with the previous study with satellite data by Liu et al. (2012) in which decreases in SIC lead to increases in cloud cover.

Although the correlation of cloud cover in October and SIC in November was strong in the MIROC5 simulations (red diamond in Fig. 4c), the autocorrelation of sea ice between October and November remained strong. Thus, changes in SIC in November may be strongly reflected by those in October rather than the impact of cloud cover in October on SIC in November. Importantly, because this correlation analysis used monthly mean data, correlations between variables on timescales smaller than 1 month remain unclear.

\subsubsection{Sensitivity experiment by using atmospheric GCM}

To further examine the effect of reduced sea ice on Arctic cloud cover, we conducted sensitivity experiments with atmospheric component of MIROC5 (MIROC5-AGCM) under different combinations of SST, sea ice, and other forcings, such as greenhouse gases, aerosols, and land use, in the 1980s to 2000s (Table 1). The setting of these experiments is described in Sect. 2.

The annual cycles of cloud cover averaged for the Arctic Ocean were reasonably simulated and similar to that in the historical MIROC5 simulations in all of the sensitivity simulations, though the cloud coverage in July and August (from October to May) was slightly smaller (larger) than that in the historical simulations (Fig. 5b). Causes of these differ- 
(a) Autocorr. sea ice (Sep-Oct)

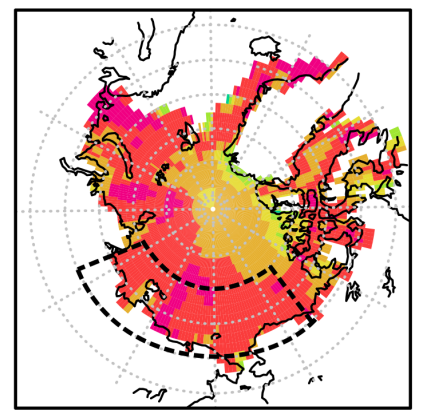

(b) Corr. cld cvr vs. sea ice (Oct)

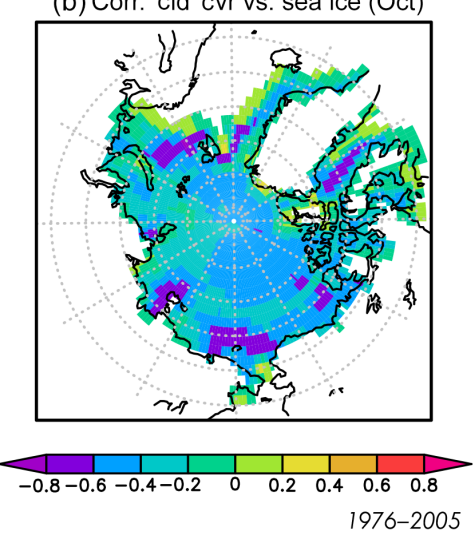

(c) Corr (Oct) 1976-2005

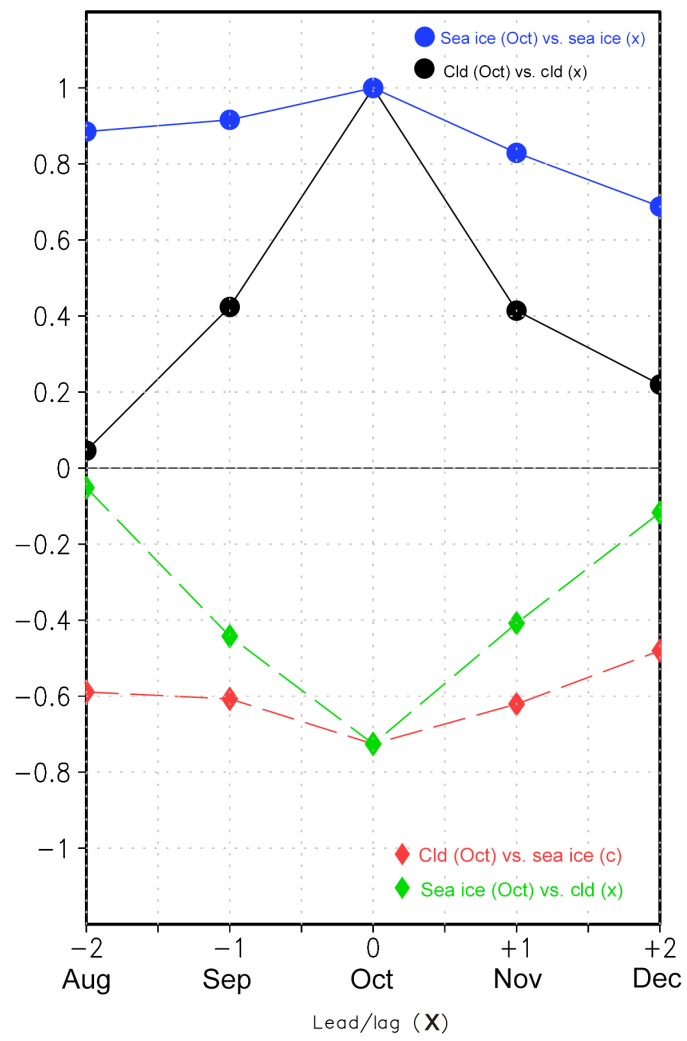

Figure 4. (a) Autocorrelation coefficients in the sea ice concentration between September and October in the MIROC5 simulations. (b) Correlation coefficients between cloud cover and sea ice concentration in October in the MIROC5 simulations. (c) Autocorrelation (closed circles) in the sea ice concentration (blue solid lines) and cloud cover (black solid lines), correlations (closed diamonds) in the lead/lagged sea ice concentrations and October cloud cover (green broken lines), and correlations in the October sea ice concentration and lead/lagged cloud cover (red broken lines) in the MIROC5 simulations. The correlation coefficients were calculated using averages for the boxed region shown in (a).

ences between the sensitivity experiments and the historical runs might be that changes in SST and sea ice and variability of interactions between atmosphere and ocean (sea ice) on timescales smaller than 1 month are not included in the sensitivity experiments, and also that the internal variability in atmospheric circulation varies between the sensitivity experiments and the historical runs.

As shown in Fig. 2c, the Arctic cloud cover is expected to increase due to a reduction in sea ice cover in SIOF2000 and ALL2000, which include a substantial reduction in Arctic sea ice. Figure $5 \mathrm{~b}$ shows the annual cycle of cloud cover differences from the CTL simulation in each experiment. During fall, the differences in the SIOF2000 and ALL2000 experiments were largest, which was similar to the historical simulations shown in Fig. 2d. On the other hand, the differences are quite small in OF2000 and SSTOF2000, which do not include a reduction in sea ice (Fig. 5b). These results clearly indicate that the Arctic cloud cover in fall increases only when sea ice cover is reduced, but that does not change remarkably when sea ice cover is not reduced. We here focused on the differences in cloud cover in October because increased cloud cover in October was the focus of the historical simulation analysis.

Geographical agreement of the differences in cloud cover and sea ice cover is important in order to prove the impact of sea ice reduction on cloud cover increase, as examined in the historical simulations (Fig. 3). The geographical maps of cloud cover in October for the CTL and ALL2000 experiments and the differences between each experiment and CTL are shown in Fig. 6. Increases in cloud cover are remarkable in the SIOF2000 and ALL2000 experiments, particularly in the grids with large sea ice reductions (Fig. $6 \mathrm{~d}$ and f). These indicate that the large increases in cloud cover are due to sea ice reduction. In contrast, there is no remarkable increases in cloud cover in the OF2000 and SSTOF2000 (Fig. 6c and e), where the sea ice reductions was not included. These results strongly imply that the sea ice reduction caused the increased cloud cover. Additionally, cloud cover increased in October when sea ice was reduced, even if the SST had remained unchanged since the 1980s (Fig. 6d). Furthermore, changes in 


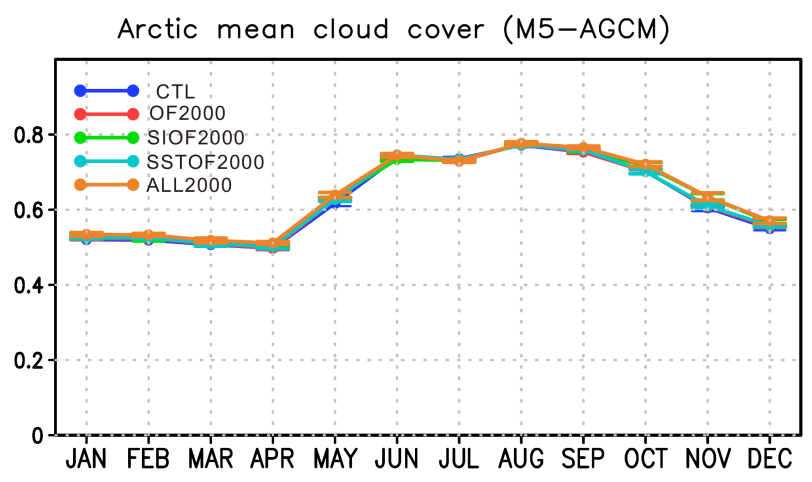

Diff. in cloud cover from CTL

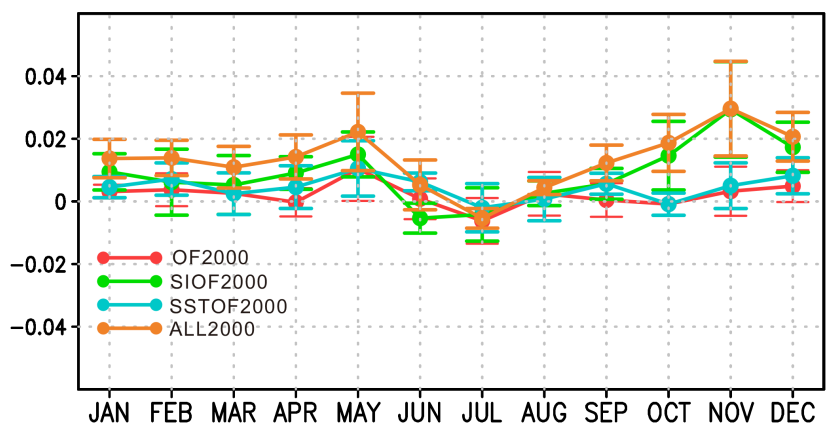

Figure 5. Seasonal cycle of (a) Arctic total cloud cover in each sensitivity simulation using MIROC5-AGCM and (b) the difference from the control experiment.

SST and other forcing conditions (except for sea ice) from the 1980s to 2000s did not increase cloud cover (Fig. 6c and e). These results agree with the results from the historical MIROC5 simulations. Therefore, we could conclude that the increased Arctic cloud cover was caused by the sea ice reductions at least in the MIROC5-AGCM simulations.

Unfortunately, using these sensitivity experiments, we could not assess the impact of increased cloud cover on sea ice reduction, which is a future consideration.

\subsection{Cloud cover changes resulting from reduced sea ice}

The following sections return to results from the historical simulations by MIROC5. As shown in Fig. 3, the retreating Arctic sea ice in September and October was substantial in the MIROC5 simulations. As a consequence of the extended open ocean, vertical heat and moisture fluxes from the ocean to the atmosphere are enhanced. Figure 7 shows the increasing trends in the latent heat (LE) and sensible heat (SH) fluxes in September and October in grids with a substantial reduction in sea ice coverage and with a larger increase in October. This is because the air temperature generally decreases more rapidly from September to October than the sea surface temperature does, leading to a larger temperature difference between the atmosphere and the sea surface in October. The increased LE and SH fluxes could play a role in the
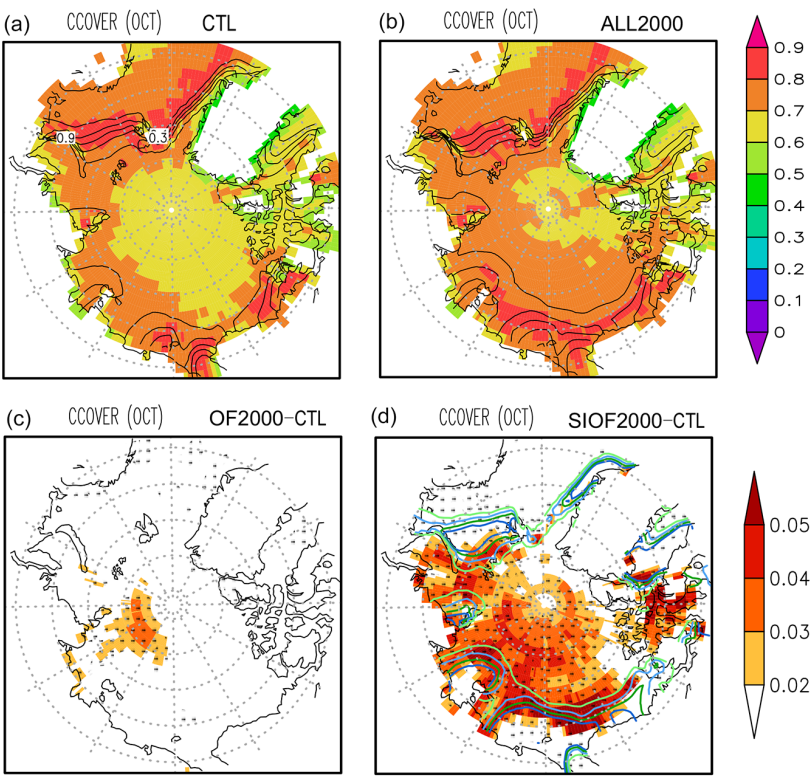

(d) CCOVER (OCT) SIOF2000-CTL

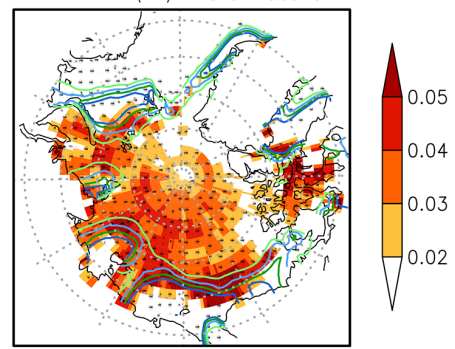

(e) CCOVER (OCT) SSTOF2000-CTL
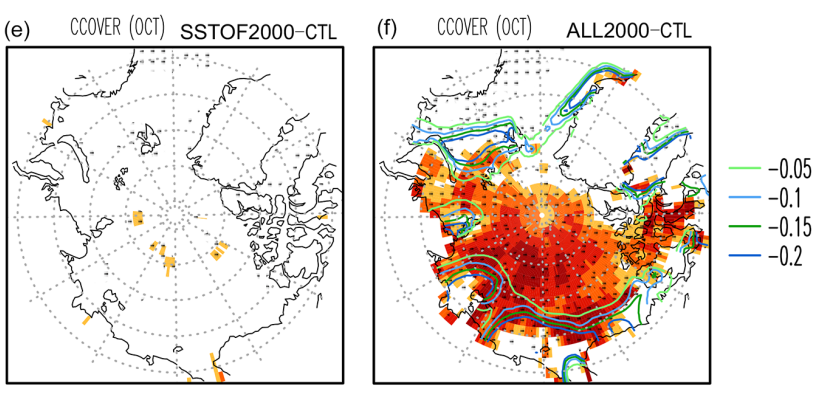

Figure 6. Geographical map of the total cloud cover (shaded) and sea ice concentration (contours) in October in the sensitivity experiments and the differences between experiments.

increased cloud cover in October through enhanced unstable atmospheric conditions and increased water vapor. These results are also consistent with previous studies (Blüthgen et al., 2012; Schweiger et al., 2008; Vavrus et al., 2011).

We compared the vertical profiles of cloud fraction, relative humidity, specific humidity, and air temperature in cases with and without the substantial reduction in sea ice and those differences between the cases in October, to clarify a mechanism of the increase in cloud due to the sea ice reduction (Fig. 8). In Fig. 8, the " $\Delta$ SI-" case is defined by grids with a substantial reduction in SIC (a linear trend in SIC of less than -0.1 decade $^{-1}$ ). As shown in Fig. 3b, many of the $\Delta$ SI - grids were located over a broad region, including the Laptev Sea, the East Siberian Sea, and the Beaufort Sea. The " $\Delta \mathrm{SI}+$ " case is defined by grids without a substantial reduction in SIC (a linear trend in SIC exceeding -0.1 decade $^{-1}$ ) over a limited latitude band (i.e., $65-73^{\circ} \mathrm{N}$ ). This limited latitude band was applied to make a comparison between the cases $(\Delta \mathrm{SI}-$ and $\Delta \mathrm{SI}+)$ in a similar latitude band. Although sea ice concentration averaged for ensemble members decreases substantially in many grids of this latitude band as 
Trend 1976-2005

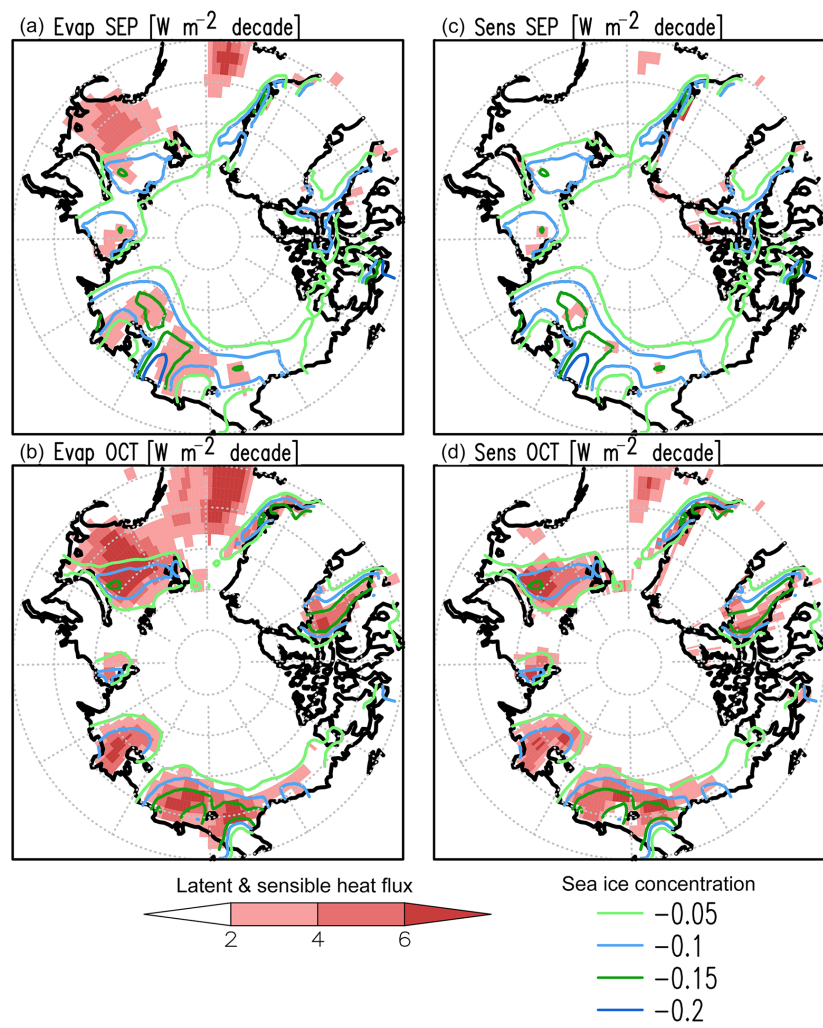

Figure 7. Geographical map of the simulated linear trend in (a, b) latent heat and (c, d) sensible heat fluxes in (a, c) September and (b, d) October during the period 1976-2005. The units are $\mathrm{W} \mathrm{m}^{-2}$ decade $^{-1}$. A linear trend for the sea ice concentration (contours) is overlaid, and the units are decade ${ }^{-1}$.

shown in Fig. 3b, there are grids without a substantial reduction in SIC in ensemble members.

In the $\Delta$ SI- case, the cloud fraction increased by approximately $4 \%$ in the lower troposphere centered at the $\sigma=0.9$ level (approximately $830 \mathrm{~m}$ ) (Fig. 8a and b). For the increased cloud fraction, the cloud liquid water increased through large-scale condensation, although the cloud ice showed little change. However, the cloud fraction decreased at levels below $\sigma=0.95$ (approximately $460 \mathrm{~m}$ ). The cloud base height rose because of the reduced sea ice in the $\Delta$ SIcase. The relative humidity increased at levels between $\sigma=$ 0.9 and $\sigma=0.8$ (approximately $1840 \mathrm{~m}$ ) and decreased below $\sigma=0.9$ for the $\Delta$ SI - case (Fig. $6 \mathrm{c}$ and d). These results were consistent with the changes in cloud fraction. The simulated vertical structures of cloud fraction and relative humidity in the later period for the $\Delta \mathrm{SI}-$ are very similar to those for low sea ice years in the ERA-Interim data set (Cuzzone and Vavrus, 2011) and those for below-normal ice concentration in the ERA-40 data set (Schweiger et al., 2008), although the values in this study differ from those in the reanalysis data sets. Furthermore, our results are consistent with those of the satellite measurements of Palm et al. (2010), which showed increased autumnal clouds near the surface (within $500 \mathrm{~m}$ ) over sea ice rather than open ocean.

The specific humidity in the lower troposphere increased more markedly in the $\Delta \mathrm{SI}-$ case than in the $\Delta \mathrm{SI}+$ case (Fig. 8e and f). The saturated specific humidity (qsat) also increased by a similar magnitude (dot-dot-dash lines in Fig. 8e and $\mathrm{f}$ ) to the increase in the specific humidity in the $\Delta \mathrm{SI}-$ case at levels where cloud fraction increased. Therefore, the relative humidity increased and enhanced the cloudiness at those levels (Fig. 8b and d). On the other hand, in thin layers near the surface, the increases in the specific humidity were smaller than those in qsat. The large increase in qsat within these thin layers was attributable to the large increases in air temperature in the $\Delta \mathrm{SI}-$ case. The air temperature increased with the maximum increase at the surface (Fig. 8g and h). Substantial increases in air temperature in the $\Delta \mathrm{SI}-$ case were found between the surface and $\sigma=0.85$ (approximately $1200 \mathrm{~m}$ ) (Fig. 8h). Therefore, in the near-surface layers, the relative humidity decreased, which would reduce cloudiness. These changes in the simulated vertical structures of air temperature and specific humidity from the earlier period to the later one for the $\Delta \mathrm{SI}-$ case correspond with differences in vertical structures of air temperature and specific humidity between low sea ice years and high sea ice years in the ERA-Interim dataset in Cuzzone and Vavrus (2011), although the differences in cloud fractions in the layers near the surface are much larger in the ERA-Interim data set.

Also in the $\Delta \mathrm{SI}+$ case, the specific humidity and air temperature increased in the lower troposphere probably because of overall warming in the Arctic due to global warming. Thus, the effect of global warming on the atmosphere, particularly in the boundary layer, appeared in a region of the Arctic Ocean without a reduction in sea ice; however, the effect was small.

\subsection{Cloud radiative forcing}

In this section, we examine the cloud radiative forcing (CRF) since cloud cover changes could affect the energy balance through the CRF. During the fall, winter, and spring seasons in the Arctic region, the DLR by clouds may play a more important role in the surface energy balance than in the lower latitudes because of the reduced or absent incoming shortwave radiation. An increase in cloud cover in the Arctic Ocean should increase the DLR at the surface; a positive change in CRF for the surface DLR could occur with the substantial reduction in SIC. In addition, an increase in the DLR because of increased water vapor and air temperature is an important factor contributing to Arctic warming (Rinke et al., 2013).

We examined the change in CRF for the surface DLR $\left(\triangle \mathrm{CRF}_{\mathrm{SDLR}}\right)$ and clear-sky surface DLR $\left(\triangle \mathrm{CS}_{\mathrm{SDLR}}\right)$ between the periods 1976-1985 and 1996-2005 for the $\Delta$ SIgrids with a substantial sea ice reduction (a linear trend in 

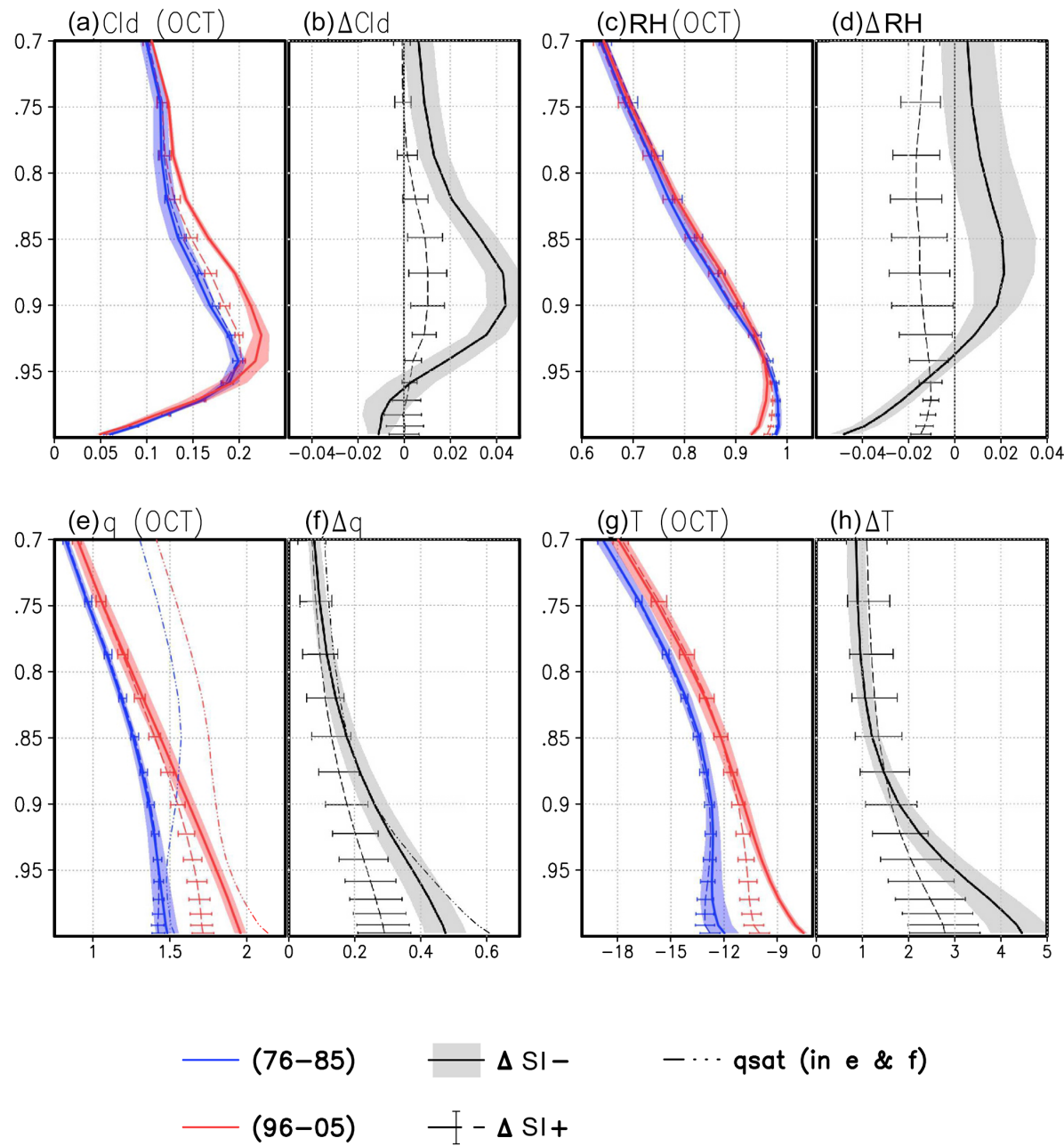

$-\cdots$ qsat (in e \& $f$ )

Figure 8. Vertical profiles of the average (a) cloud fraction, (c) relative humidity (RH), (e) specific humidity, and (g) air temperature in October in the MIROC5 simulations for the periods 1976-1985 (blue) and 1996-2005 (red). The solid (broken) line represents the $\Delta$ SI$(\Delta \mathrm{SI}+)$ case. See the text for the definitions of the $\Delta \mathrm{SI}-$ and $\Delta \mathrm{SI}+$ cases. Vertical profiles of the differences between average (b) cloud fraction, (d) relative humidity, (f) specific humidity, and (h) air temperature in October in the MIROC5 simulations for the periods 19761985 and 1991-2005. The solid (broken) line represents the $\Delta$ SI- ( $\Delta$ SI+) case. The dot-dot-dash lines in (e) and (f) indicate the saturated specific humidity. The units of air temperature and specific humidity are $\mathrm{K}$ and $\mathrm{g} \mathrm{kg}^{-1}$, respectively. Shading and error bars indicate the standard deviations for the ensemble members in the $\Delta \mathrm{SI}-$ and $\Delta \mathrm{SI}+$ cases, respectively.

SIC of less than -0.1 decade $^{-1}$ ) and $\Delta$ SI + grids without a substantial sea ice reduction (a linear trend in SIC exceeding -0.1 decade $^{-1}$ ) in each month (Fig. 9a). Positive $\triangle \mathrm{CS}_{\mathrm{SDLR}}$ was found in both cases. Positive $\Delta \mathrm{CS}_{\mathrm{SDLR}}$ was dominant in the $\Delta \mathrm{SI}-$ case when compared with the $\Delta \mathrm{SI}+$ case, particularly during fall, winter, and spring. This positive $\triangle \mathrm{CS}_{\mathrm{SDLR}}$ resulted from both warming and moistening due to the increased open ocean and global warming. Thus, positive $\Delta \mathrm{CS}_{\mathrm{SDLR}}$ due to increased water vapor and air temperature can largely affect the surface energy balance in the grids with substantially reduced SIC.

$\triangle \mathrm{CRF}_{\mathrm{SDLR}}$ in the $\triangle \mathrm{SI}-$ case were also large and positive from September to April; the changes in the $\Delta \mathrm{SI}+$ case were small. This result indicated that the increased CRF of surface
DLR was not negligible and potentially contributed to the increased radiation energy in the surface in the grids with substantially reduced SIC, but the large positive $\triangle \mathrm{CS}_{\mathrm{SDLR}}$ was more dominant than $\triangle \mathrm{CRF}_{\mathrm{SDLR}}$.

In contrast, during summer, $\triangle \mathrm{CS}_{\mathrm{SDLR}}$ was moderately positive and $\triangle C_{\text {RF }}$ SDLR was marginally negative in both cases, although the differences between both cases were very small. This result indicated that reduced sea ice was unlikely to enhance differences in the variation of surface DLR during summer in the MIROC5 simulations.

To evaluate the relative importance of the changes in CRF of surface DLR to the changes in clear-sky surface DLR, we defined an index as the ratio of $\triangle \mathrm{CRF}_{\mathrm{SDLR}}$ to $\triangle \mathrm{CS}_{\mathrm{SDLR}}$ $\left((\Delta \mathrm{CRF} / \Delta \mathrm{CS})_{\mathrm{SDLR}}\right)$. The sign of the indexes was the same 
(a) $\triangle \mathrm{CRF}_{\text {SOLR }} \& \mathrm{CS} S_{\text {SOLR }}\left[\mathrm{W} \mathrm{m}^{-2}\right](1996-2005)-(1976-1985)$

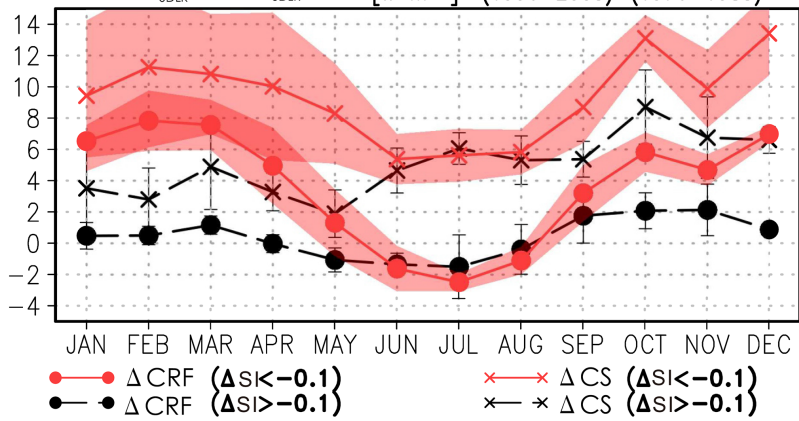

(b) $(\triangle \mathrm{CRF} / \Delta \mathrm{CS})_{\text {SOLR }}$

$(1996-2005)-(1976-1985)$

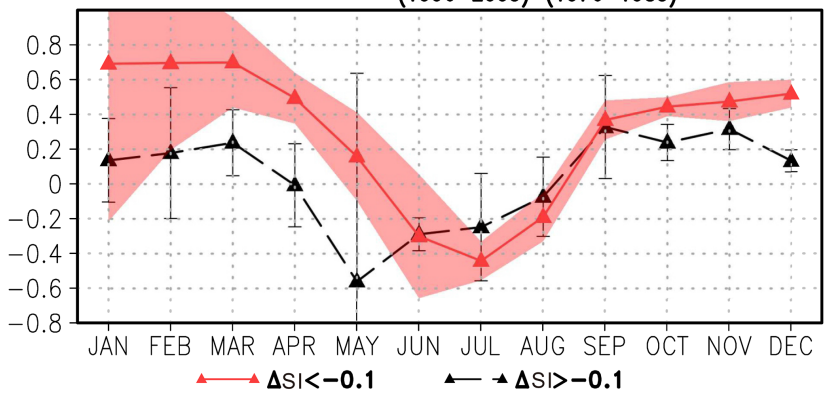

Figure 9. Annual time series of (a) the change in (crosses) the CRF in surface DLR ( $\left.\triangle \mathrm{CRF}_{\mathrm{SDLR}}\right)$ and (closed circles) clear-sky surface DLR $\left(\triangle \mathrm{CS}_{\mathrm{SDLR}}\right)$ between the averages for 1976-1985 and 1996-2005 in the MIROC5 simulations and (b) the index $\left((\Delta \mathrm{CRF} / \Delta \mathrm{CS})_{\mathrm{SDLR}}\right.$, the ratio of $\Delta \mathrm{CRF}_{\mathrm{SDLR}}$ to $\left.\Delta \mathrm{CS}_{\mathrm{SDLR}}\right)$. The solid red (broken black) lines indicate the $\Delta \mathrm{SI}-(\Delta \mathrm{SI}+)$ case. See the text for the definition of the index. Shading and error bars indicate the standard deviations for the ensemble members in the $\Delta$ SIand $\Delta \mathrm{SI}+$ cases, respectively.

as that of $\triangle \mathrm{CRF}_{\mathrm{SDLR}}$ since $\triangle \mathrm{CS}_{\mathrm{SDLR}}$ was positive in all the months (Fig. 9a and b). The indexes for the $\Delta$ SI- case was negative in summer, increased approximately from 0.4 to 0.5 during September-December, reached a maximum (approximately 0.7 ) in January-March, and decreased in spring (Fig. 9b). However, it was difficult to obtain a statistically significant result for the indexes during winter and spring, since the uncertainties of the indexes (shading in Fig. 9b) were large from January to June due to the small sample numbers of $\Delta \mathrm{SI}-$ grids in those months. Furthermore, the indexes in summer for both cases were similar since there were no substantial differences in $\triangle \mathrm{CRF}_{\mathrm{SDLR}}$ and $\triangle \mathrm{CS}_{\mathrm{SDLR}}$ between the two cases (Fig. 9a).

By contrast, uncertainties in the indexes from October to December were small in both the $\Delta \mathrm{SI}-$ and $\Delta \mathrm{SI}+$ cases. An increase in the cloud cover as a result of reduced sea ice enhanced the surface DLR. The indexes during the period October-December showed that the all-sky surface DLR in the $\Delta$ SI- cases increased by approximately $40-60 \%$ compared with the clear-sky surface DLR. The indexes in the $\Delta \mathrm{SI}-$ cases were larger than those in the $\Delta \mathrm{SI}+$ cases, al- (a) Trend SLP \& quv925 [/decade]

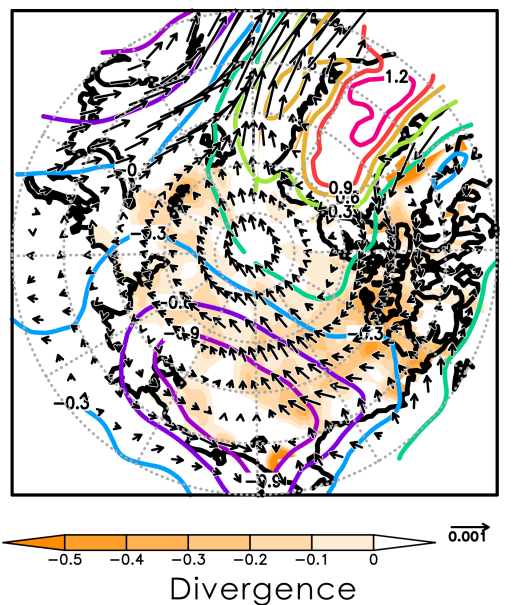

(b) Trend d $\theta$ e/dz $[\mathrm{K} / 100 \mathrm{~m} /$ decade $]$

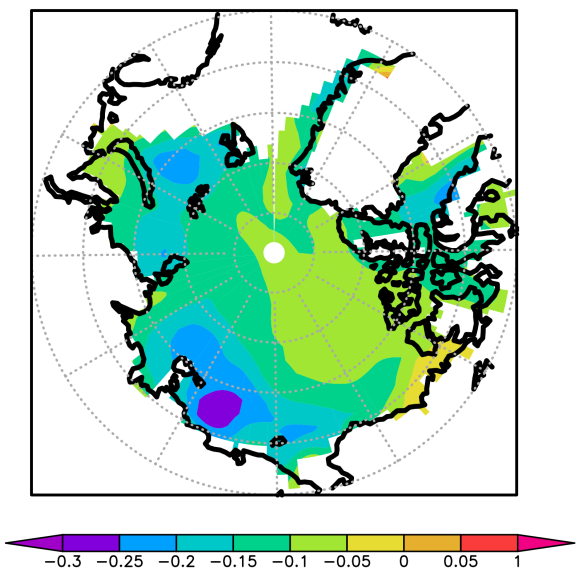

Figure 10. (a) Simulated linear trend in sea level pressure (SLP, contours), moisture flux at $925 \mathrm{hPa}$ (quv925, vectors), and convergence(shade). The unit of the moisture flux trend is $\left(\mathrm{kg} \mathrm{kg}^{-1}\right)$ $\left(\mathrm{m} \mathrm{s}^{-1}\right)$ decade $^{-1}$. (b) Simulated linear trend in the lapse rate of the equivalent potential temperature $(\mathrm{d} \theta e / \mathrm{d} z: \theta e$ indicates the equivalent potential temperature; $z$ indicates geopotential height) between the surface and $\sigma=0.9$. The unit for the lapse rate of the equivalent potential temperature is $\mathrm{K}(100 \mathrm{~m})^{-1}$ decade $^{-1}$. The values were averaged over all ensemble members.

though the index in the $\Delta \mathrm{SI}-$ grids in November was not clearly distinguished from that in the $\Delta \mathrm{SI}+$ grids. Thus, considering the reduction in sea ice in October, the change in the CRF due to reduced sea ice was not disregarded as a factor affecting Arctic warming. This finding disagrees with Rinke et al. (2013). This can be attributed to the different definition in their study and ours. The averaged value over the Arctic Ocean for Fig. 9b, as in their study, would become close to those for the $\Delta \mathrm{SI}+$ case in winter and early spring because the area with significant sea ice reduction was small during these seasons. 
We also compared the change in CRF of the surface downward shortwave radiation (DSR) with clear-sky surface DSR in both the $\Delta \mathrm{SI}-$ and $\Delta \mathrm{SI}+$ cases. The change in the CRF of the surface DSR in the $\Delta \mathrm{SI}+$ case was a small fraction of the clear-sky surface DSR over the year. The result in the $\Delta$ SI- case showed that the change in the CRF of the surface DSR was less than $10 \%$ of clear-sky surface DSR during summer, fall and winter, and the change during spring had a large uncertainty in the $\Delta$ SI- case. In addition, clear-sky surface DSR was close to zero during winter. Therefore, we concluded that the impact of cloud cover changes resulting from reduced sea ice on the surface DSR was small during the fall.

\section{Discussion}

As shown in Fig. 3b, increases in the simulated cloud cover were found in the Arctic Ocean near the North Pole, where simulated sea ice did not decrease substantially. We investigated the effect of changes in both the moisture convergence and the static stability in the lower troposphere on the simulated increased cloud cover. Figure 10a shows the simulated linear trend in the sea level pressure (SLP), moisture flux at $925 \mathrm{hPa}$, and the convergence in October, which were averages of the ensemble members. The figure shows that the moisture flux converged in the region with increased cloud cover. Therefore, the cloud cover in the region near the North Pole increased in the lower troposphere due to the enhanced moisture convergence despite the absence of a significant reduction in sea ice. However, we found by analyzing the data in each ensemble member that increases in moisture convergence in regions without large reductions in sea ice did not lead to increased cloud cover in some of the ensemble members. Therefore, enhanced moisture convergence may be insufficient to result in increased cloud cover. Furthermore, Fig. 10b shows the simulated linear trend in the lapse rate of equivalent potential temperature between the surface and $\sigma=0.9$, which was also averaged for the ensemble members. The figure shows that the static stability in the lower troposphere decreased over most of the Arctic Ocean, although large decreases in static stability did not always correspond with large increases in cloud cover in regions without large reductions in sea ice. This result was common in each ensemble member. Therefore, an appropriate and systematic cause of the large increases in cloud cover over the region without a substantial reduction in sea ice remains unclear. It may be possible that the moisture injected into the Arctic during October in recent years could be trapped more effectively within lower-tropospheric layers above the colder perennial ice pack and thus promote more cloudiness in the later period. To clarify this finding, more ensemble members may be required in the experiment.

Under global warming conditions, both air temperature and humidity increase, complicating the changes in Arctic cloud cover. Therefore, considering future Arctic cloud cover changes, increases in both air temperature and humidity are crucial components in addition to sea ice loss. With regard to the vertical profile of cloud cover changes, the level at which air temperature and humidity increase under global warming conditions is important. Thus, fine vertical resolution and boundary processes in the model may be primary factors for improving the projections of Arctic cloud cover change related to global warming and sea ice loss in the future.

Previous studies have argued for the role of changes in Arctic cloud cover in Arctic warming. Significantly increased DLR due to cloud cover occurred in grids with significant reductions in sea ice, whereas select studies have noted a reduced effect caused by the increase in cloud cover on the surface DLR. These discrepancies should be related to the uncertainties of clouds and cloud radiative forcing in individual models. The vertical profile of changes in cloud cover is also strongly related to changes in cloud radiative forcing. Uncertainty in air temperature and humidity increases may be among the causes. Therefore, further investigations into Arctic cloud cover changes and feedback processes related to clouds are needed.

With regard to the feedback between sea ice and clouds, the effects of cloud cover on sea ice are also considerable. This study focused on the changes in Arctic cloud cover as a result of reduced sea ice. However, we were unable to observe an effect of increased cloud cover on sea ice reduction in our statistical analysis of inter-seasonal variations using monthly mean data despite the increased surface DLR resulting from increased cloud cover.

\section{Summary}

This study investigated Arctic cloud cover changes resulting from reduced sea ice due to global warming simulated by MIROC5 to understand the effect of changes in the extent of Arctic sea ice on cloud cover. A large negative trend was found for Arctic sea ice in the MIROC5 simulations in summer and fall during the period 1976-2005, although small negative trends in the winter and spring were found in limited regions. The temporal trend in the simulated Arctic cloud cover was positive in fall, winter, and spring, reaching a maximum in October. This study focused on increases in the cloud fraction in October resulting from reduced sea ice.

Results of the autocorrelation and the lead-lag correlation analysis suggest increase in cloud cover during October is attributable to a reduction in sea ice cover. Further, sensitivity experiments with the different combinations of SIC, SST, and other forcing conditions in the 1980s and 2000s using the atmospheric part of MIROC5 proved that a reduction in sea ice cover causes an increase in cloud cover; this result supports results of the lead-lag correlation analysis.

In the grids with reduced SICs (trends of less than -0.1 decade $^{-1}$ ) in the MIROC5 simulations, the cloud frac- 
tion in October increased at levels between $\sigma=0.9$ and $\sigma=0.7$. Because of the reduced sea ice, a more extended open ocean area increased the latent and sensible heat fluxes from the ocean to the atmosphere. Along with the seasonal march, the decreased atmospheric temperatures increased the temperature gradient between the air and sea surface in October. Therefore, the fluxes from the ocean to the atmosphere were enhanced in October rather than in September. This effect resulted in a greater increase in the cloud fraction in October than in September. However, the cloud fraction decreased in the near-surface layers in the MIROC5 simulations because extreme warming was found in these layers.

There were several ensemble members in which the cloud cover increased in regions close to the North Pole, where no substantial reductions in sea ice were simulated. However, a plausible cause for this increase in the simulated cloud cover remains unclear despite our analysis on the changes in water vapor convergence and the static stability in the lower troposphere in each ensemble member. To clarify this dichotomy, more ensemble members may be required in the experiment.

The change in CRF as a result of reduced sea ice in the surface DLR was approximately 40-60\% compared with a change in clear-sky surface DLR, which was considered as a change in the surface DLR due to increases in air temperature and water vapor in grids with large sea ice reductions in fall. Therefore, the change in CRF resulting from reduced sea ice must be considered as a factor influencing Arctic warming.

This study analyzed data from only one climate model, i.e., MIROC5. Therefore, future research topics include the sea-ice-cloud cover relationship in multiple models and its contribution to the uncertainty of future climate change projections. In the future, if the sea ice retreats further in summer, fall, and spring, then the Arctic cloud cover could increase further, and the effects of cloud cover could become stronger. Thus, further understanding and correct projections of the relationship between sea ice and cloud cover are important for the analysis of future global and Arctic climate change.

\section{Data availability}

Data of the historical simulations and the sensitivity experiments by MIROC5 reported in this study are available upon request to the first author (abe.mnb@gmail.com).

Data of the historical simulations by MIROC5 also are available from the data server of the Coupled Model Intercomparison Project 5 (CMIP5) (https://pcmdi.llnl.gov/ projects/cmip5/).

Acknowledgements. We thank Y. Komuro and T. Suzuki for providing the land fraction data for MIROC5 to enable the calculations of the Arctic sea ice area. Additionally, we thank two anonymous referees for the valuable comments to improve the manuscript. This study was supported by the GRENE Arctic Climate Change
Research Project, the Arctic Challenge for Sustainability (ArCS) Project, and the Program for Risk Information on Climate Change (SOUSEI program) conducted by the Ministry of Education, Culture, Sports, Science and Technology, Japan. The Earth Simulator at JAMSTEC was employed to perform the GCM simulations.

Edited by: J. Quaas

Reviewed by: two anonymous referees

\section{References}

Blüthgen, J., Gerdes, R., and Werner, M.: Atmospheric response to the extreme Arctic sea ice conditions in 2007, Geophys. Res. Lett., 39, L02707, doi:10.1029/2011g1050486, 2012.

Comiso, J. C., Parkinson, C. L., Gersten, R., and Stock, L.: Accelerated decline in the Arctic sea ice cover, Geophys. Res. Lett., 35, L01703, doi:10.1029/2007GL031972, 2008.

Curry, J. A., Schramm, J. L., and Ebert, E. E.: Sea Ice-Albedo Climate Feedback Mechanism, J. Climate, 8, 240-247, 1995.

Cuzzone, J. and Vavrus, S.: The relationships between Arctic sea ice and cloud-related variables in the ERA-Interim reanalysis and CCSM3, Environ. Res. Lett., 6, 014016, doi:10.1088/17489326/6/1/014016, 2011.

Dickinson, R., Meehl, G., and Washington, W.: Ice-albedo feedback in a CO2-doubling simulation, Climatic Change, 10, 241-248, 1987.

Hahn, C. J., Warren, S. G., and London, J.: The Effect of Moonlight on Observation of Cloud Cover at Night, and Application to Cloud Climatology, J. Climate, 8, 1429-1446, 1995.

Hansen, J., Ruedy, R., Sato, M., and Lo, K.: GLOBAL SURFACE TEMPERATURE CHANGE, Rev. Geophys., 48, RG4004, doi:10.1029/2010RG000345, 2010.

Hasumi, H.: CCSR Ocean Component Model (COCO), version 4.0, Center for Climate System Research, The University of Tokyo, Center for Climate System Research Rep 25, 103 pp., 2007.

Holland, M. M. and Bitz, C. M.: Polar amplification of climate change in coupled models, Clim. Dynam., 21, 221-232, 2003.

Kay, J. E. and Gettelman, A.: Cloud influence on and response to seasonal Arctic sea ice loss, J. Geophys. Res.-Atmos., 114, D18204, doi:10.1029/2009JD011773, 2009.

Komuro, Y., Suzuki, T., Sakamoto, T. T., Hasumi, H., Ishii, M., Watanabe, M., Nozawa, T., Yokohata, T., Nishimura, T., Ogochi, K., Emori, S., and Kimoto, M.: Sea-Ice in Twentieth-Century Simulations by New MIROC Coupled Models: A Comparison between Models with High Resolution and with Ice Thickness Distribution, Journal of Meteorological Society of Japan, 90A, 213-232, 2012.

Lean, J., Rottman, G., Harder, J., and Kopp, G.: SORCE Contributions to New Understanding of Global Change and Solar Variability, Sol. Phys., 230, 27-53, 2005.

Liu, Y., Key, J. R., Liu, Z., Wang, X., and Vavrus, S. J.: A cloudier Arctic expected with diminishing sea ice, Geophys. Res. Lett., 39, L05705, doi:10.1029/2012g1051251, 2012.

Manabe, S. and Stouffer, R. J.: Sensitivity of a global climate model to an increase of $\mathrm{CO}_{2}$ concentration in the atmosphere, J. Geophys. Res.-Oceans, 85, 5529-5554, 1980.

Morice, C. P., Kennedy, J. J., Rayner, N. A., and Jones, P. D.: Quantifying uncertainties in global and regional tempera- 
ture change using an ensemble of observational estimates: The HadCRUT4 data set, J. Geophys. Res.-Atmos., 117, D08101, doi:10.1029/2011JD017187, 2012.

Palm, S. P., Strey, S. T., Spinhirne, J., and Markus, T.: Influence of Arctic sea ice extent on polar cloud fraction and vertical structure and implications for regional climate, J. Geophys. Res.-Atmos., 115, D21209, doi:10.1029/2010JD013900, 2010.

Perovich, D. K., Light, B., Eicken, H., Jones, K. F., Runciman, K., and Nghiem, S. V.: Increasing solar heating of the Arctic Ocean and adjacent seas, 1979-2005: Attribution and role in the ice-albedo feedback, Geophys. Res. Lett., 34, L19505, doi:10.1029/2007GL031480, 2007.

Porter, D. F., Cassano, J. J., and Serreze, M. C.: Local and largescale atmospheric responses to reduced Arctic sea ice and ocean warming in the WRF model, J. Geophys. Res.-Atmos., 117, D11115, doi:10.1029/2011JD016969, 2012.

Rayner, N. A., Parker, D. E., Horton, E. B., Folland, C. K., Alexander, L. V., Rowell, D. P., Kent, E. C., and Kaplan, A.: Global analyses of sea surface temperature, sea ice, and night marine air temperature since the late nineteenth century, J. Geophys. Res.Atmos., 108, 4407, doi:10.1029/2002JD002670, 2003.

Rinke, A., Dethloff, K., Dorn, W., Handorf, D., and Moore, J. C.: Simulated Arctic atmospheric feedbacks associated with late summer sea ice anomalies, J. Geophys. Res.-Atmos., 118, 7698$7714,2013$.

Sato, K., Inoue, J., Kodama, Y.-M., and Overland, J. E.: Impact of Arctic sea-ice retreat on the recent change in cloudbase height during autumn, Geophys. Res. Lett., 39, L10503, doi:10.1029/2012g1051850, 2012.

Sato, M., Hansen, J. E., McCormick, M. P., and Pollack, J. B.: Stratospheric aerosol optical depths, 1850-1990, J. Geophys. Res.-Atmos., 98, 22987-22994, 1993.

Schweiger, A. J., Lindsay, R. W., Key, J. R., and Francis, J. A.: Arctic clouds in multiyear satellite data sets, Geophys. Res. Lett., 26, 1845-1848, 1999.
Schweiger, A. J., Lindsay, R. W., Vavrus, S., and Francis, J. A.: Relationships between Arctic Sea Ice and Clouds during Autumn, J. Climate, 21, 4799-4810, 2008.

Screen, J. A. and Simmonds, I.: Increasing fall-winter energy loss from the Arctic Ocean and its role in Arctic temperature amplification, Geophys. Res. Lett., 37, L16707, doi:10.1029/2010GL044136, 2010.

Serreze, M. C. and Barry, R. G.: Processes and impacts of Arctic amplification: A research synthesis, Global Planet. Change, 77, 85-96, 2011.

Smith, T. M., Reynolds, R. W., Peterson, T. C., and Lawrimore, J.: Improvements to NOAA's Historical Merged Land-Ocean Surface Temperature Analysis (1880-2006), J. Climate, 21, 22832296, 2008.

Vavrus, S., Waliser, D., Schweiger, A., and Francis, J.: Simulations of 20th and 21st century Arctic cloud amount in the global climate models assessed in the IPCC AR4, Clim. Dynam., 33, 1099-1115, 2009.

Vavrus, S., Holland, M. M., and Bailey, D. A.: Changes in Arctic clouds during intervals of rapid sea ice loss, Clim. Dynam., 36, 1475-1489, 2011.

Watanabe, M., Suzuki, T., O'ishi, R., Komuro, Y., Watanabe, S., Emori, S., Takemura, T., Chikira, M., Ogura, T., Sekiguchi, M., Takata, K., Yamazaki, D., Yokohata, T., Nozawa, T., Hasumi, H., Tatebe, H., and Kimoto, M.: Improved Climate Simulation by MIROC5: Mean States, Variability, and Climate Sensitivity, J. Climate, 23, 6312-6335, 2010.

Wu, D. L. and Lee, J. N.: Arctic low cloud changes as observed by MISR and CALIOP: Implication for the enhanced autumnal warming and sea ice loss, J. Geophys. Res.-Atmos., 117, D07107, doi:10.1029/2011JD017050, 2012.

Yoshimori, M., Abe-Ouchi, A., Watanabe, M., Oka, A., and Ogura, T.: Robust Seasonality of Arctic Warming Processes in Two Different Versions of the MIROC GCM, J. Climate, 27, 6358-6375, 2014. 